\title{
MAP Kinase Pathways
}

\section{Deborah K. Morrison}

Laboratory of Cell and Developmental Signaling, National Cancer Institute, Frederick, Maryland 21702

Correspondence: morrisod@mail.nih.gov

Mitogen-activated protein kinase (MAPK) modules containing three sequentially activated protein kinases are key components of a series of vital signal transduction pathways that regulate processes such as cell proliferation, cell differentiation, and cell death in eukaryotes from yeast to humans (Fig. 1) (Qi and Elion 2005; Raman et al. 2007; Keshet and Seger 2010). Each cascade is initiated by specific extracellular cues and leads to activation of a particular MAPK following the successive activation of a MAPK kinase kinase (MAPKKK) and a MAPK kinase (MAPKK) (Fig. 1). The MAPKKK is typically activated by interactions with a small GTPase and/or phosphorylation by protein kinases downstream from cell surface receptors (Cuevas et al. 2007). The MAPKKK directly phosphorylates and activates the MAPKK, which, in turn, activates the MAPK by dual phosphorylation of a conserved tripeptide TxY motif in the activation segment. Once activated, the MAPK phosphorylates diverse substrates in the cytosol and nucleus to bring about changes in protein function and gene expression that execute the appropriate biological response. MAPKs generally contain docking sites for MAPKKs and substrates, which allow high-affinity protein-protein interactions to ensure both that they are activated by a particular upstream MAPKK (Bardwell and Thorner 1996) and that they recognize specific downstream targets (Tanoue and Nishida 2003).

The MAP kinases can be grouped into three main families. In mammals, these are ERKs (extracellular-signal-regulated kinases), JNKs (Jun amino-terminal kinases), and p38/SAPKs (stress-activated protein kinases). ERK family

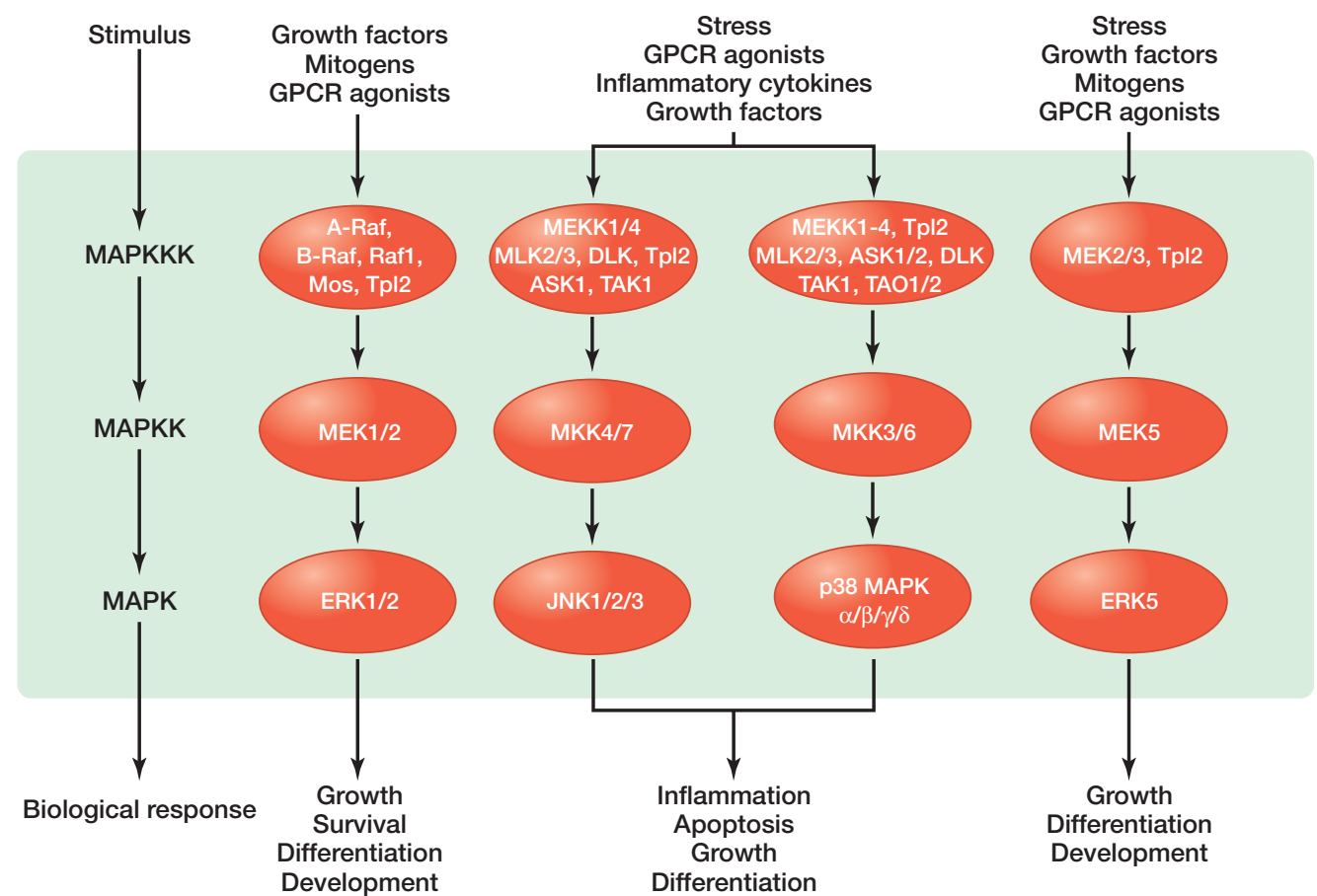

Figure 1. MAPK pathways.

Editors: Lewis Cantley, Tony Hunter, Richard Sever, and Jeremy Thorner

Additional Perspectives on Signal Transduction available at www.cshperspectives.org. 


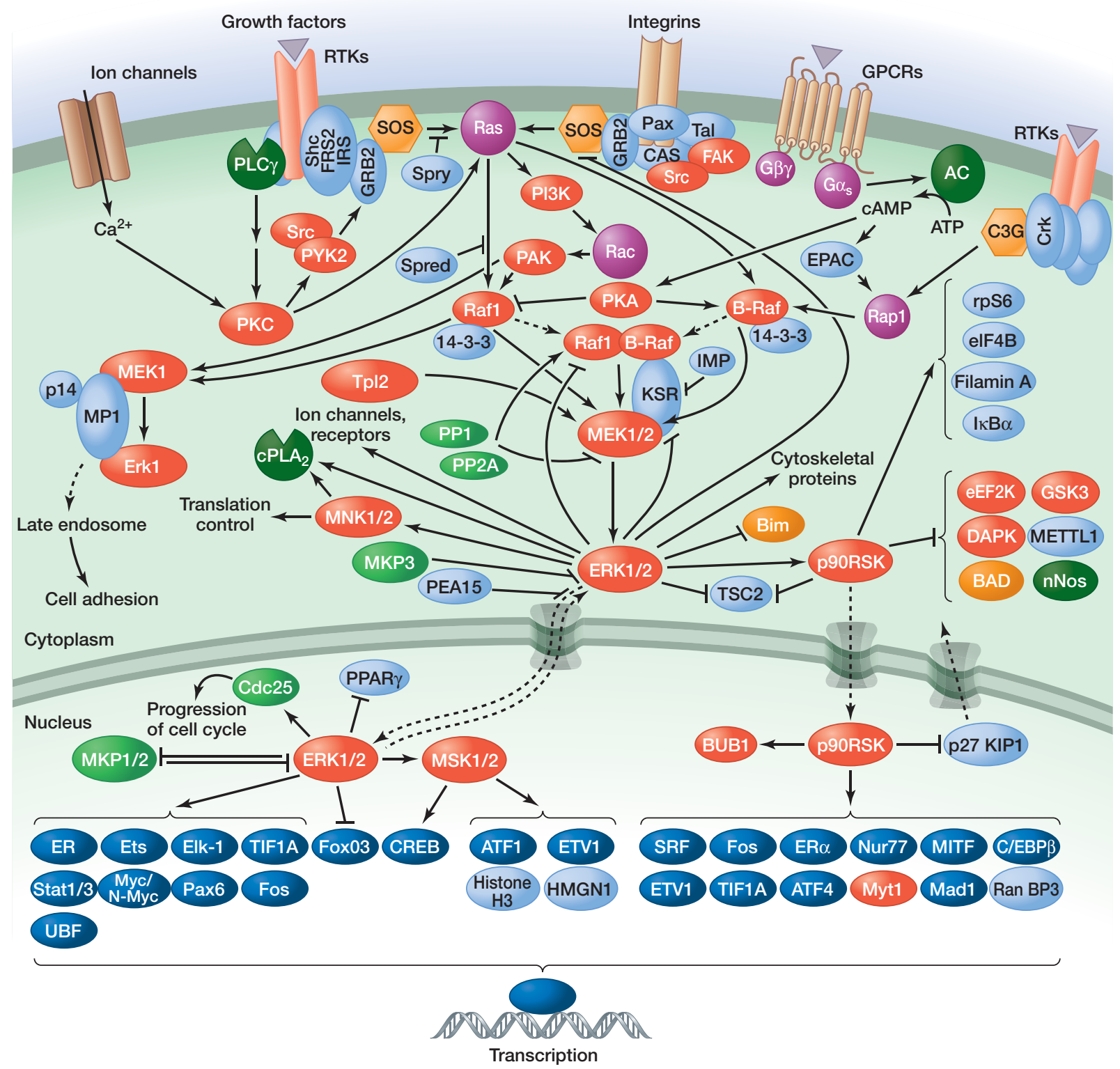

Figure 2. The ERK MAPK pathway.

members possess a TEY motif in the activation segment and can be subdivided into two groups: the classic ERKs that consist mainly of a kinase domain (ERK1 and ERK2) and the larger ERKs (such as ERK5) that contain a much more extended sequence carboxy-terminal to their kinase domain (Zhang and Dong 2007). The classic ERK1/2 module (Fig. 2) responds primarily to growth factors and mitogens to induce cell growth and differentiation (McKay and Morrison 2007; Shaul and Seger 2007). Important upstream regulators of this module include cell surface receptors, such as receptor tyrosine kinases (RTKs), G-protein-coupled receptors (GPCRs), and integrins, as well as the small GTPases Ras and Rap. MAPKKs for the classic ERK1/2 module are MEK1 and MEK2, and the MAPKKKs include members of the Raf family, Mos, and Tpl2.

JNK family members contain a TPY motif in the activation segment and include JNK1, JNK2, and JNK3. The JNK module (Fig. 3) is activated by environmental stresses (ionizing radiation, heat, oxidative stress, and DNA damage) and inflammatory cytokines, as well as growth factors, and signaling to the JNK module often involves the Rho family GTPases Cdc42 and Rac (Johnson and Nakamura 2007). The JNK module plays an important role in apoptosis, inflammation, cytokine production, and 


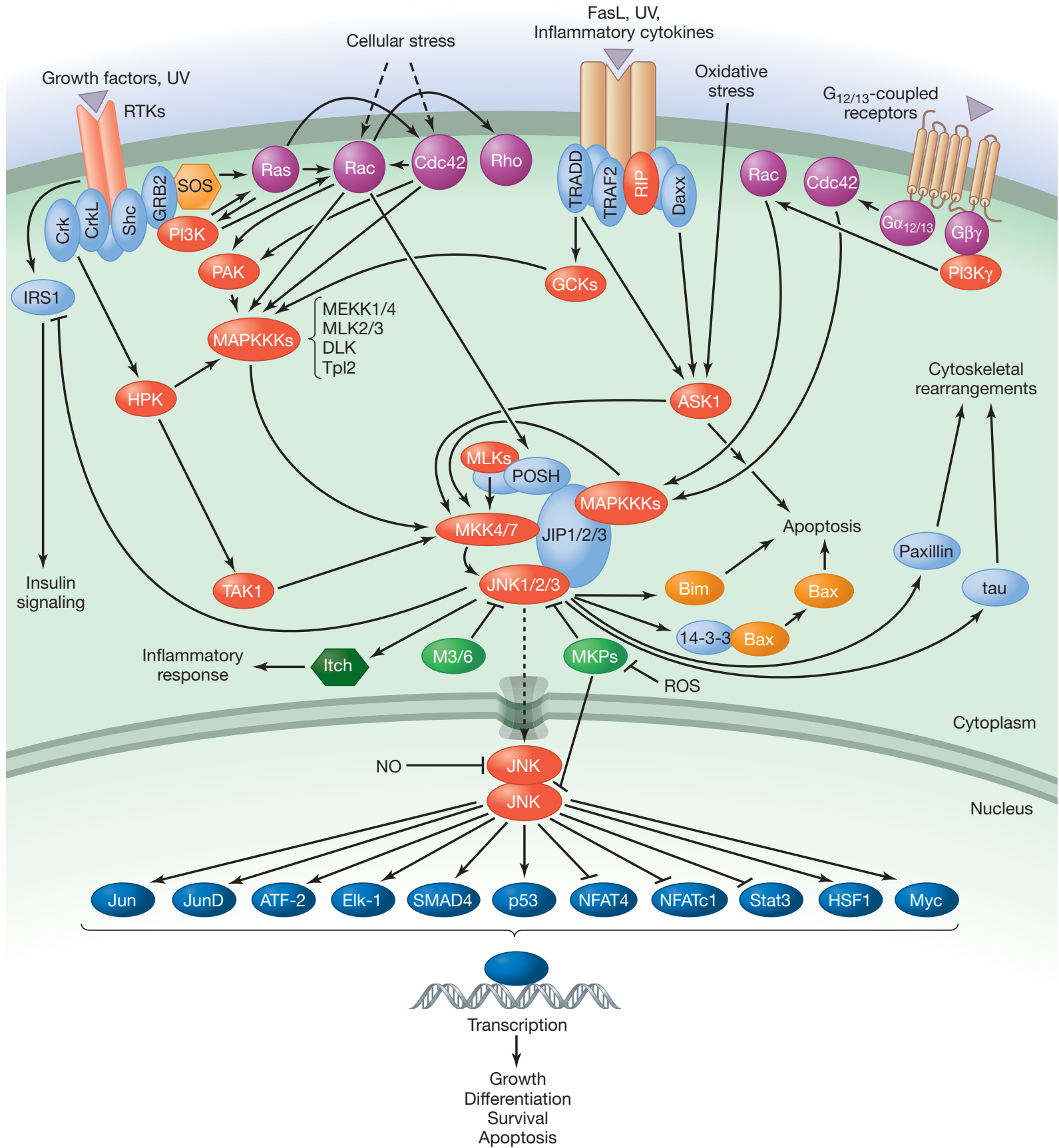

Figure 3. The JNK MAPK pathway.

metabolism (Dhanasekaran and Reddy 2008; Huang et al. 2009; Rincon and Davis 2009). MAPKKs for the JNK module are MKK4 and MKK7, and the MAPKKKs include MEKK1 and MEKK4, MLK2 and MLK3, ASK1, TAK1, and Tpl2.

p38 family members possess a TGY motif in the activation segment and include $\mathrm{p} 38 \alpha, \mathrm{p} 38 \beta, \mathrm{p} 38 \gamma$, and $\mathrm{p} 38 \delta$. Like JNK modules, p38 modules (Fig. 4) are strongly activated by environmental stresses and inflammatory cyto- kines. p38 activation contributes to inflammation, apoptosis, cell differentiation, and cell cycle regulation (Cuenda and Rousseau 2007; Cuadrado and Nebreda 2010). The primary MAPKKs for p38 modules are MKK3 and MKK6, and the MAPKKKs include MLK2 and MLK3, MEKKs, ASKs, TAK1, and TAO1 and TAO2. Important substrates in $\mathrm{p} 38$ signaling include the downstream kinases MK2/3, PRAK, and MSK1 and MSK2, as well as various transcription factors. 


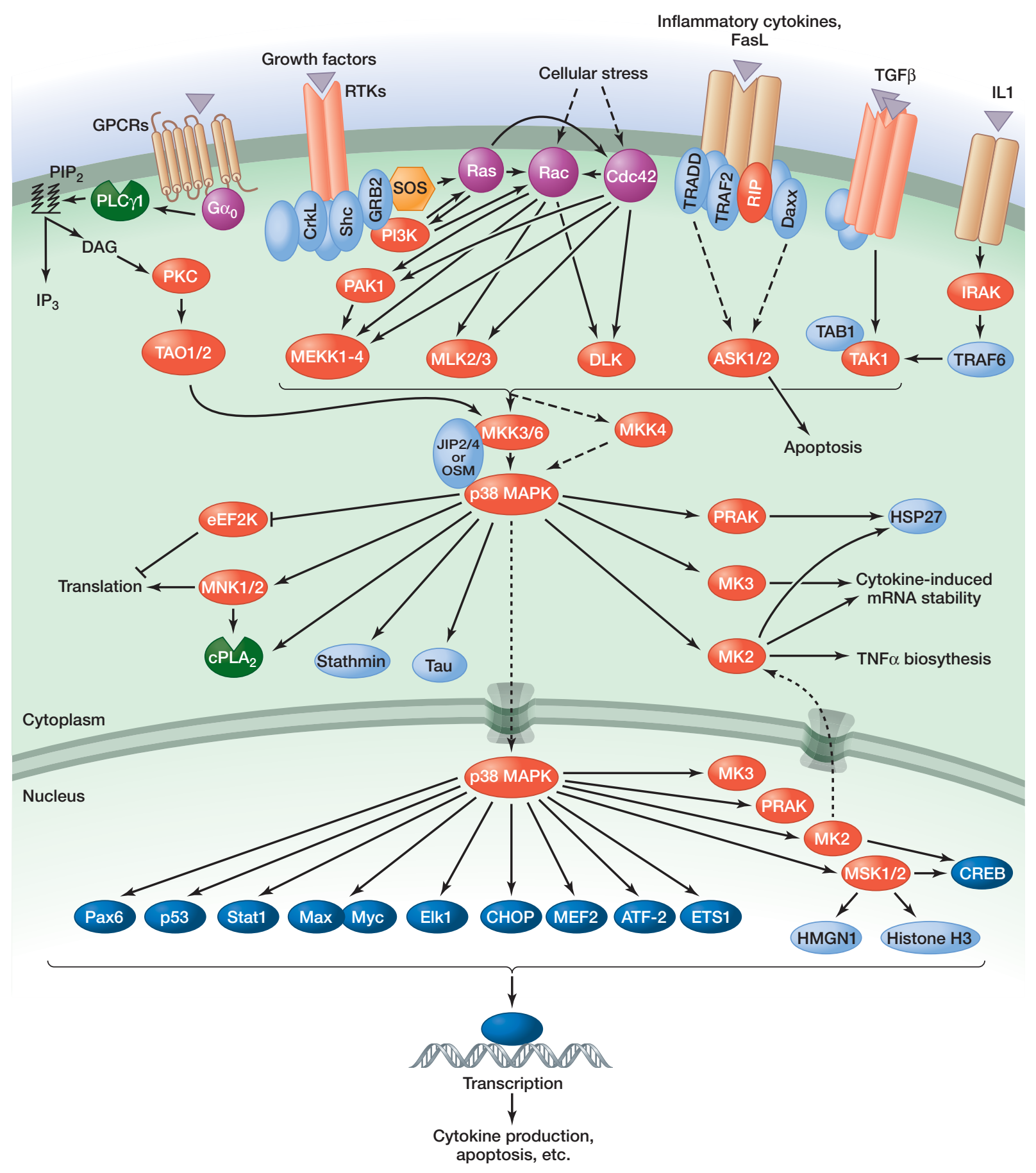

Figure 4. The p38 MAPK pathway.

For all of the MAPK modules, specific scaffold proteins (Good et al. 2011) have been identified that dock at least two of the core kinases of the module. These scaffolds contribute to MAPK signaling by increasing the local concentration of the components, providing spatial temporal regulation of cascade activation, and/or localizing the module to specific cellular sites or substrates. Scaffold proteins involved in MAPK cascade signaling include KSR and MP1 for the ERK module; JIP1, JIP2, JIP3, JIP4, and POSH for the JNK module; and JIP2, JIP4, and OSM for the p38 module (Dhanasekaran et al. 2007).

Figure 1 adapted, with permission, from Cell Signaling Technology (http:// www.cellsignal.com). 


\section{REFERENCES}

Bardwell L, Thorner J. 1996. A conserved motif at the amino termini of MEKs might mediate high-affinity interaction with the cognate MAPKs. Trends Biochem Sci 21: 373-374.

Cuadrado A, Nebreda AR. 2010. Mechanisms and functions of p38 MAPK signalling. Biochem J 429: 403-417.

Cuenda A, Rousseau S. 2007. p38 MAP-kinases pathway regulation, function and role in human diseases. Biochim Biophys Acta 1773: 1358-1375.

Cuevas BD, Abell AN, Johnson GL. 2007. Role of mitogen-activated protein kinase kinase kinases in signal integration. Oncogene 26: 3159-3171.

Dhanasekaran DN, Reddy EP. 2008. JNK signaling in apoptosis. Oncogene 27: 6245-6251.

Dhanasekaran DN, Kashef K, Lee CM, Xu H, Reddy EP. 2007. Scaffold proteins of MAP-kinase modules. Oncogene 26: 3185-3202.

Good MC, Zalatan JG, Lim WA. 2011. Scaffold proteins: Hubs for controlling the flow of cellular information. Science 332: 680-686.

Huang G, Shi LZ, Chi H. 2009. Regulation of JNK and p38 MAPK in the immune system: Signal integration, propagation and termination. Cytokine 48: 161-169.
Johnson GL, Nakamura K. 2007. The c-Jun kinase/stress-activated pathway: Regulation, function and role in human disease. Biochim Biophys Acta 1773: $1341-1348$.

Keshet Y, Seger R. 2010. The MAP kinase signaling cascades: A system of hundreds of components regulates a diverse array of physiological functions. Methods Mol Biol 661: 3-38.

McKay MM, Morrison DK. 2007. Integrating signals from RTKs to ERK/ MAPK. Oncogene 26: 3113-3121.

Qi M, Elion EA. 2005. MAP kinase pathways. J Cell Sci 118: 3569-3572.

Raman M, Chen W, Cobb MH. 2007. Differential regulation and properties of MAPKs. Oncogene 26: 3100-3112.

Rincon M, Davis RJ. 2009. Regulation of the immune response by stressactivated protein kinases. Immunol Rev 228: 212-224.

Shaul YD, Seger R. 2007. The MEK/ERK cascade: From signaling specificity to diverse functions. Biochim Biophys Acta 1773: 1213-1226.

Tanoue T, Nishida E. 2003. Molecular recognitions in MAP kinase cascades. Cell Signal 15: 455-462.

Zhang Y, Dong C. 2007. Regulatory mechanisms of mitogen-activated kinase signaling. Cell Mol Life Sci 64: 2771-2789. 


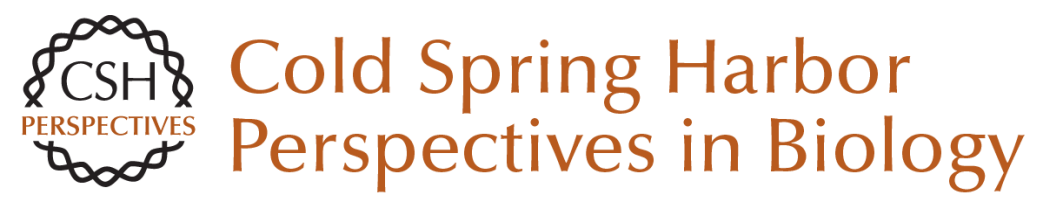

\section{MAP Kinase Pathways}

Deborah K. Morrison

Cold Spring Harb Perspect Biol 2012; doi: 10.1101/cshperspect.a011254

Subject Collection Signal Transduction

Cell Signaling and Stress Responses Gökhan S. Hotamisligil and Roger J. Davis

Protein Regulation in Signal Transduction Michael J. Lee and Michael B. Yaffe

Synaptic Signaling in Learning and Memory Mary B. Kennedy

Vertebrate Reproduction Sally Kornbluth and Rafael Fissore

Signaling in Lymphocyte Activation Doreen Cantrell

Signaling in Muscle Contraction Ivana Y. Kuo and Barbara E. Ehrlich

Toll-Like Receptor Signaling Kian-Huat Lim and Louis M. Staudt

Signaling Pathways that Regulate Cell Division Nicholas Rhind and Paul Russell
Second Messengers

Alexandra C. Newton, Martin D. Bootman and John D. Scott

Signals and Receptors Carl-Henrik Heldin, Benson Lu, Ron Evans, et al.

Cell Death Signaling Douglas $R$. Green and Fabien Llambi

Signaling Networks that Regulate Cell Migration Peter Devreotes and Alan Rick Horwitz

Signaling Networks: Information Flow, Computation, and Decision Making Evren U. Azeloglu and Ravi lyengar

Signal Transduction: From the Atomic Age to the Post-Genomic Era Jeremy Thorner, Tony Hunter, Lewis C. Cantley, et al.

Signaling by the TGF $\beta$ Superfamily Jeffrey L. Wrana

Subversion of Cell Signaling by Pathogens Neal M. Alto and Kim Orth

For additional articles in this collection, see http://cshperspectives.cshlp.org/cgi/collection/

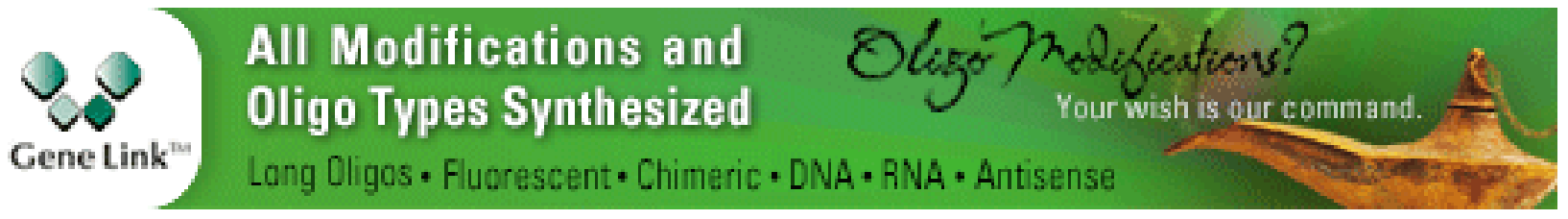

Copyright @ 2012 Cold Spring Harbor Laboratory Press; all rights reserved 